9. Engelman DT, Crisafi C, Germain M, Greco B, Nathanson BH, Engelman RM, et al. Using urinary biomarkers to reduce acute kidney injury following cardiac surgery. J Thorac Cardiovasc Surg. October 17, 2019 [Epub ahead of print].

10. Baribeau Y, Westbrook B, Baribeau Y, Maltais S, Boyle EM, Perrault LP. Active clearance of chest tubes is associated with reduced postoperative complications and costs after cardiac surgery: a propensity matched analysis. $J$ Cardiothorac Surg. 2019;14:192
11. Fleming IO, Garratt C, Guha R, Desai J, Chaubey S, Wang Y, et al. Aggregation of marginal gains in cardiac surgery: feasibility of a perioperative care bundle for enhanced recovery in cardiac surgical patients. J Cardiothorac Vasc Anesth. 2016;30:665-70

12. Engelman DT, Ben Ali W, Williams JB, Perrault LP, Reddy VS, Arora RC, et al. Guidelines for perioperative care in cardiac surgery: enhanced recovery after surgery society recommendations. JAMA Surg. 2019;154:755-66.
See Article page 880.

\section{Commentary: Acute kidney injury, a multi-billion-dollar issue}

\author{
Thomas S. Metkus, MD, ${ }^{\mathrm{a}}$ and
}

Glenn J. R. Whitman, MD ${ }^{\mathrm{b}}$

Acute kidney injury (AKI) is a devastating, common complication of critical illness in general and cardiac surgery in particular. Knowledge gaps remain in defining the epidemiology and associated outcomes. Lau and colleagues ${ }^{1}$ present an analysis addressing some of these unknowns. In more than 10,000 cardiac surgical patients, $25 \%$ experienced AKI, by Kidney Disease: Improving Global Outcomes (KDIGO) criteria. ${ }^{2}$ The $3 \%$ requiring dialysis suffered a 37 -fold increase in mortality risk and an almost 3-fold increase in hospital costs. Even those with AKI stage 1 and 2 experienced a 3- to 9 -fold increase in mortality and a $20 \%$ to $50 \%$ increase in cost. Moreover, poor outcomes and high costs persisted out of hospital out to 1 year after. These results are in keeping with those found by Cho and colleagues, ${ }^{3}$ confirming that any AKI places cardiac surgical patients at high risk even in the months after surgery. These data highlight the urgent need for action from surgeons, health care systems, and all those participating in the

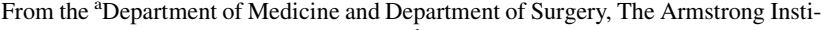
tute for Patient Safety and Quality, and ${ }^{\mathrm{b}}$ Department of Surgery, Division of Cardiac Surgery, Johns Hopkins University School of Medicine, Baltimore, Md.

Disclosures: Dr Metkus performs consulting unrelated to this subject matter for BestDoctors Inc and Oakstone/EBIX. Dr Metkus receives royalties for a textbook publication for McGraw-Hill publishing, unrelated to this subject matter. Dr Whitman reported no conflicts of interest.

The Journal policy requires editors and reviewers to disclose conflicts of interest and to decline handling or reviewing manuscripts for which they may have a conflict of interest. The editors and reviewers of this article have no conflicts of interest.

Received for publication May 15, 2020; accepted for publication May 17, 2020; available ahead of print June 5, 2020.

Address for reprints: Glenn J. R. Whitman, MD, Division of Cardiac Surgery, Department of Surgery, Johns Hopkins School of Medicine, 1800 Orleans St, Zayed

Tower, Suite 7107, Baltimore, MD 21287 (E-mail: gwhitman@jhmi.edu).

J Thorac Cardiovasc Surg 2021;162:891-2

$0022-5223 / \$ 36.00$

Copyright (C) 2020 by The American Association for Thoracic Surgery

http://dx.doi.org/10.1016/j.jtcvs.2020.05.070
}

Check for updates

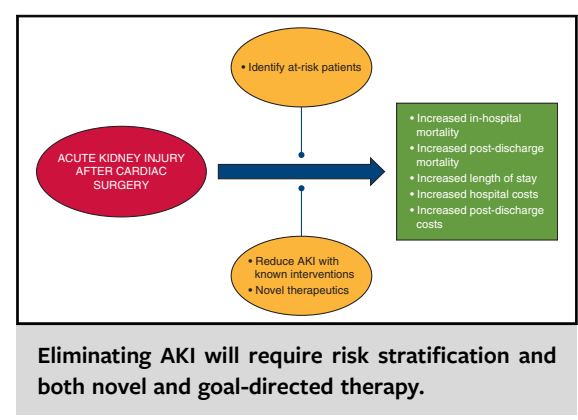

CENTRAL MESSAGE

Acute kidney injury is associated

with high costs and poor out-

comes in-hospital and beyond,

providing an impetus for both

clinicians and health care sys-

tems to dedicate resources

aimed at its prevention.

preoperative, perioperative, and postoperative phases of care (Figure 1).

Is AKI a preventable injury ${ }^{4}$ ? Both intraoperative as well as postoperative goal-directed protocols ${ }^{5,6}$ can significantly reduce AKI. Other results corroborate the authors ${ }^{7}$; assuming roughly 400,000 patients undergoing cardiac surgery per year, the incremental cost of AKI is on the order of several billion dollars.

The impact of AKI illustrated by Lau and colleagues serves as a clarion call to reduce the burden of AKI, thereby improving patient and health system outcomes. Novel biomarkers to identify high-risk patients are emerging. Hayek and colleagues ${ }^{8}$ recently identified soluble urokinase plasminogen activator receptor as strongly associated with AKI after cardiac surgery. This work also suggests a novel therapeutic approach-in an experimental mouse model, pretreatment with a urokinase plasminogen activator 


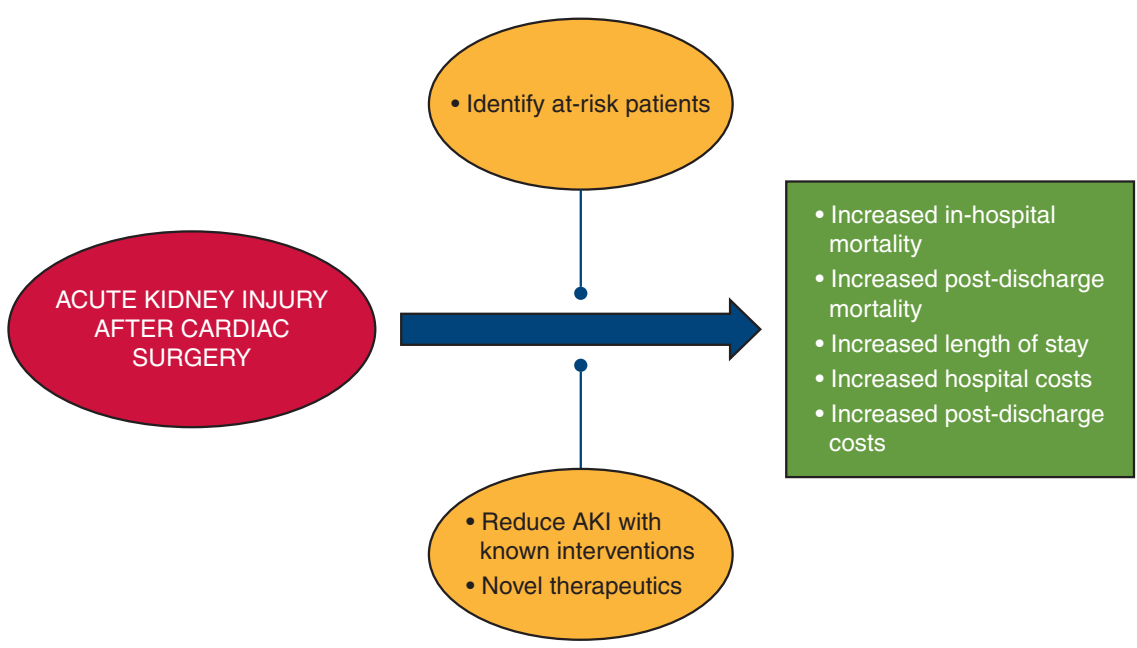

FIGURE 1. Eliminating AKI will require risk stratification and both novel and goal-directed therapy. AKI, Acute kidney injury.

receptor monoclonal antibody mitigated the rise in creatinine and the development of histopathologic features of $\mathrm{AKI}$ in response to a renal toxin.

Thus, the work of Lau and colleagues sets the stage and establishes the urgency to address AKI at the population level. One should not overlook the tools already at our disposal to reduce AKI, including attention to fluid status, avoidance of renal toxins, consideration of goal-directed cardiopulmonary bypass and hemodynamic management, and the use of an enhanced recovery after surgery (ie, ERAS) bundle. Additional items on the research agenda should include attention to quality of life outcomes and the degree to which non-renal comorbidities impact the risks and outcomes of renal failure. This effort will require focusing on the patient preoperatively, intraoperatively, and postoperatively, and success (perhaps best called renal success) will not only improve the health of individuals but also unnecessary health care expenditures.

\section{References}

1. Lau D, Pannu N, James MT, Hemmelgarn BR, Kieser TM, Meyer SR, et al. Costs and consequences of acute kidney injury after cardiac surgery: a cohort study. $J$ Thorac Cardiovasc Surg. 2021;162:880-7.

2. Kellum JA, Lameire N, Aspelin P, Barsoum RS, Burdmann EA, Goldstein SL, et al. Kidney disease: improving global outcomes (KDIGO) acute kidney injury work group. KDIGO clinical practice guideline for acute kidney injury. Kidney In Suppl. 2012;2:1-138

3. Cho JS, Shim J-K, Lee S, Song J-W, Choi N, Lee S, et al. Chronic progression of cardiac surgery associated acute kidney injury: intermediary role of acute kidney disease. J Thorac Cardiovasc Surg. November 9, 2019 [Epub ahead of print].

4. Whitman GJR, Parikh CR. Commentary: The dangers of postoperative acute kidney injury-vulnerability despite early resolution. J Thorac Cardiovasc Surg. November 9, 2019 [Epub ahead of print]

5. Magruder JT, Crawford TC, Harness HL, Grimm JC, Suarez-Pierre A, Wierschke C, et al. A pilot goal-directed perfusion initiative is associated with less acute kidney injury after cardiac surgery. J Thorac Cardiovasc Surg. 2017;153:118-25.e1.

6. Johnston LE, Thiele RH, Hawkins RB, Downs EA, Jaeger JM, Brooks C, et al. Goaldirected resuscitation following cardiac surgery reduces acute kidney injury: a quality initiative pre-post analysis. J Thorac Cardiovasc Surg. 2020;159:1868-77.e1.

7. Dasta JF, Kane-Gill S. Review of the literature on the costs associated with acute kidney injury. J Pharm Pract. 2019;32:292-302.

8. Hayek SS, Leaf DE, Samman Tahhan A, Raad M, Sharma S, Waikar SS, et al. Soluble urokinase receptor and acute kidney injury. N Engl J Med. 2020;382:416-26. 